\title{
Setting the Conditions
}

I have been struck again and again by how important measurement is to improving the human condition.

BILL GATES, ANNUAL LETTER, 2013

As insiders know, the production of good things is not pretty. Workers are caught in a web of demands that compel them to deviate from formal and idealistic rules. Yet for public consumption, practitioners must present glossy versions of how they work. These illusions are essential for occupational survival. When the work is messy, workers have to clean up well.

GARY ALAN Fine AND DAVID SHULMAN, "LIES FROM THE FIELD."

In October 2012, the affluent Lima neighborhood of Miraflores was adorned with eye-catching purple-and-orange posters and banners advertising Social Inclusion Week. The week, which was intended "to call attention to poor and vulnerable populations and their opportunities for development," marked the one-year anniversary of the Ministry of Development and Social Inclusion (MIDIS 2012d). ${ }^{1}$ The theme for the week was "women as partners in development," and a number of posters depicted female figures in Western and traditional indigenous dress. ${ }^{2}$ MIDIS proclaimed that the week would "pay homage to the women users of social programs, who are agents and partners in the progress of their households and communities" (MIDIS 2012d, original emphasis). ${ }^{3}$

Social Inclusion Week was one of several moments in the country's history where women have been called upon to participate in improving the nation. The organized week bore a striking resemblance to a Mothers' Day celebration in the early 1990s when then-president Alberto Fujimori also paid homage to the nation's women, praising them as self-sacrificing mothers and "heroines" (Boesten 2010). At the time, Fujimori called upon women in their caring roles to soften the blow of austerity measures in households and communities. In practice, self-sacrifice and "heroism" had a gendered cost; development scholar Jelke Boesten showed that for many low-income women, austerity meant assuming an even larger load 
of unpaid care work where the state had retreated, even as opportunities for paid work were shrinking. Poor Peruvian women "were perceived first as mothers and carers of other people, and only thereafter as citizens in their own right" (Boesten 2010, 39). While the intentions may have been good, this framing of women and their contributions had the effect of exacerbating women's marginalized economic status and masking their own unmet needs.

Two decades later, Social Inclusion Week provided a view into the more recent turn in Latin American development policy and how women featured in it. Following the election of President Ollanta Humala in 2011, social inclusion became the driving development paradigm in Peru, as it had in a number of other Latin American countries. By creating MIDIS, Humala fulfilled a campaign promise, charging the ministry with coordinating action across the country to fight poverty and social exclusion. MIDIS did so primarily through social programs but also through monitoring compliance with agreements, evaluating impacts, and sharing knowledge. ${ }^{4}$ The government oriented its social inclusion policy toward achieving a situation in which all people throughout Peru exercise their rights, have access to high-quality public services, and are able to make use of the opportunities opened up by economic growth.

Central to the policy are ethnic and geographical dimensions: it holds that all Peruvians shall participate equally in their communities, regardless of their ethnicity or place of birth or residence (MIDIS 2012c). 5 The creation of a ministry devoted specifically to smoothing out long-standing patterns of geographical and ethnic exclusion was significant. MIDIS targeted the implementation of its programs to rural areas populated primarily by indigenous and campesino communities that had previously experienced neglect on the part of the state, which had failed to make investments in the basic services and infrastructure required for good health, economic prosperity, and well-being in those communities. ${ }^{6}$

One of the ministry's most striking accomplishments has been ensuring that previously undocumented rural residents possess state identification cards that permit them access to government services, including social programs and public health insurance. Among the initiatives that ID cards specifically allow women to access is Juntos, the conditional cash transfer program. Today, Juntos is Peru's farthest-reaching mechanism for social inclusion. In 2013, the program ensured that 1.5 million children attended school and had regular health checkups, and that over seventeen thousand pregnant women attended prenatal appointments (Juntos 2015b).

Peru is not exceptional in its use of a CCT program to implement a program of inclusion. In no small part because of World Bank support and financing, CCTs are the most widely used tool for promoting inclusive development in countries across the global south (Cecchini and Madariaga 2011). According to indicators for geographical coverage and service uptake, Juntos is reasonably considered a successful intervention. Yet it is worth considering how much these indicators 
actually tell us about the capacity of CCTs to include the poor. The women represented on the posters and banners for Social Inclusion Week provided a moment for critical reflection: how did they feature in social inclusion policy? Were the aspects of their own exclusion addressed, and were their contributions to a more inclusive Peru accounted for?

In the air-conditioned offices and conference rooms of Lima, policy makers and state bureaucrats at MIDIS and Juntos make decisions that affect how the CCT is rolled out in regions far away. I call these actors "experts." Some wield more power than others; the "high-level experts" that I interviewed hold or held a considerable amount of authority and influence, including the minister of development and social inclusion, the executive director of Juntos, members of the now-defunct Juntos Directive Council, and leaders of governmental and nongovernmental national women's organizations. Other experts are university-educated professionals at Juntos and MIDIS who are responsible for policy and program administration. They could also be called bureaucrats or technocrats. The aspirations of these experts are important to the story of Juntos, and to the fraught process of translating good intentions into a manageable-and measureable-intervention, and so this chapter begins with them.

\section{GOOD INTENTIONS: INCLUDING THE POOR THROUGH RIGHTS AND ACCESS TO SERVICES}

Tucked deep within Lima's grungier city center, the windowless meeting space of the General Confederation of Peruvian Workers reverberated with the sounds of organizing in the adjacent rooms. Under fluorescent lights and flanked by red-andwhite posters from Peru's long-standing labor union movement, a former member of the Juntos Directive Council spoke to me about poor people's rights. ${ }^{7}$ Like others associated with Juntos in similar positions of administration and power, she emphasized that for the poor, the cash payment was a citizenship right: "You can't give these hundred soles like charity: 'Hey take this handout,' no? [Instead] you have to say, 'This is part of the government, it's your part!' Right? We deliver it, but it corresponds to the citizenship of our country! ... And [Juntos recipients] shouldn't feel humiliated or mistreated or owing favors: 'Look, please, the hundred soles...' No, no, none of this. Rather, it is their right."

In Peru, as elsewhere, many supporters of CCT programs spoke about the cash transfer as a citizenship right. ${ }^{8}$ In another corner of the city among the big-box warehouses and dried-fish stink of the industrial sector, the director of the Catholic aid organization Caritás Peru, also a former member of the Juntos Directive Council, had similar views. Seated in a stuffed swivel chair beneath a simple wooden crucifix, he patiently explained to me that it was important that "the program's impact doesn't remain just an issue of economic subsidy, but becomes a process for reinforcing citizenship." 
The difference between charity and a citizenship right in these narratives is significant because it delineates particular roles for the government and its citizens. First, charity is a voluntary, benevolent act toward the poor in which the giver's obligations derive from a higher moral purpose rather than the poor themselves (Spicker et al. 2007). From this perspective, if the CCT were charity, the state would not be under any obligation to provide it. Second, recipients of charity are traditionally conceived of as passive actors with little agency. Given that they have no claim to entitlement, the role of recipient is to await a handout. In a charitable arrangement, the less powerful are positioned at the behest of more powerful others. In contrast, citizenship rights imply an obligation on the part of the state. Juntos, like other CCTs, emerged out of a growing consensus in the mid-199os regarding the need for government to actively participate in addressing the persistent poverty and exclusion of groups for whom "the market" had consistently failed to provide. ${ }^{9}$ In Peru, as elsewhere, this shift has materialized in efforts to reach the poor through social programs.

Shortly after Social Inclusion Week, I attended a conference called "The Role of Women in Development," which was open to the public and raised a number of related themes. The conference was hosted in the theater of the French Alliance's stately colonial building, and besuited panelists from both government and civil society, spoke about the role of social programs in mitigating poverty. Among the panelists was the minister of MIDIS, a well-respected rural development economist. In addition to emphasizing MIDIS's approach to delivering rights and services, the minister stressed the role of the government in redressing inequality. She said, "We need social programs to stop being seen as a generous help from the state. It's the state's obligation to provide [social] services to those populations for which the state hasn't been able to guarantee exercise of rights or good opportunities. So while we aren't able to guarantee these things, we need to have social programs." The minister went further, insisting that in addition to social programs, the state was obligated to provide resources, including water, electricity, and health posts offering primary care: "There is a set of basic services that the state has to provide for the poorest populations, and it has to provide all of it."

This notion of state obligation was consistent with the idea of coresponsibility upon which CCT programs like Juntos are grounded. The state agreed to provide the social services that support health and education, and households agreed to make adequate use of these. Through implementation of this contract, Juntos strove to achieve its vision, "to have restored the basic rights of households[,] whose members have regular access to quality basic services in education, health and nutrition, corresponding to full exercise of their citizenship, and to have improved their quality of life and human capital development, thereby reducing the intergenerational transfer of poverty" (Juntos 2015a). While experts reproduced the narrative around poor people's access to rights and quality public services and the state's obligation to provide these, operationalizing these good intentions was another matter entirely. 


\section{THE POOR CONDITIONS OF HEALTH AND EDUCATION SERVICES}

While policy makers and bureaucrats at MIDIS and Juntos oversaw high-level administration of the CCT and made new iterations of the program's design and implementation as necessary, they did not control the quality and availability of public services that women and their children were incentivized to access. Health and education were the purview of the Ministry of Health (MINSA) and the Ministry of Education (MINEDU). In effect, Juntos stimulated demand for health and education services, while the distinct entities of MINSA and MINEDU were responsible for supplying those services. The configuration of this relationship had significant implications for how Juntos functioned on the ground, and for women's and children's experiences of the program.

During Juntos's early years (2006-2011), the program was housed within the Presidential Council of Ministers. In this cabinet, Juntos was governed by the Directive Council, which was constituted by representatives from MINSA, MINEDU, and other ministries, and by members of civil society. This institutional arrangement was designed to bring disparately situated entities into productive dialogue. According to the accounts of Directive Council members, the previous model of governance allowed the program to provide the health and education sectors with information regarding demand for services (e.g., where improvements to service provision were needed). In turn, the relevant ministries were supposed to be better equipped to attend to the matter of improving service supply.

However, Directive Council members reported that the coordinating potential of the council was never realized. In part, this was due to conflict over program ownership and budget. At the time, ministerial resolutions allocated 30 percent of Juntos's budget to health, education, and other relevant sectors, such that the Ministry of Health and the Ministry of Education each received 10 percent of Juntos's total budget (MINEDU 2009; MINSA 2006; see also UNDP 2006). Yet tensions arose because the funds were aligned with an agenda crafted by Juntos, and the health and education sectors were not granted the autonomy to allocate funds as they saw fit. Juntos presided over the use of funds through signed agreements, creating a hierarchical tension that complicated cooperation (UNDP 2006, 32). In an interview, a high-level development expert reflected on Juntos's frustrated efforts to implement improvements to health and education services: "The experience of Juntos forcing these sectors to make things better has been really bad in previous years. Around five years ago Juntos even had money that it gave these sectors, money to make the service offering better. And it didn't work at all. It didn't work at all. ... It gave them the money and nothing happened."

Another factor that contributed to the Directive Council's inability to coordinate service delivery related to political culture. There was a perceived failure on the part of the council to explicitly confront the poor quality of services, as 
explained by another high-level development expert: "What was lost from this model? That there was a space, to take information about the precarious state of health and education services to the health and education ministries. But [the Directive Council] was never used for this. Rather there was much care taken such that it was never openly stated how bad health and education could actually be. So it was eliminated, because it didn't fulfill its role." When Juntos was moved to MIDIS in 2012, the Directive Council was dissolved and, along with it, the institutionally sanctioned space for dialogue between Juntos, MINSA, and MINEDU.

After the move, some attempts to coordinate the efforts of Juntos and the health and education sectors were made. One of these was a tripartite convention that assigned MINSA and MINEDU responsibility for providing an adequate supply of services in the places where Juntos intervened. However, despite the agreement, the supply of health and education services in many areas remained inadequate to meet the demand that Juntos generated. In an interview, a high-level expert at MIDIS expressed frustration at the situation:

So what are we doing now? Because we noticed that you can encourage, encourage,
encourage families to go [to the services], but if the school doesn't change, and if the
health centers don't have vaccines, [children's health and education aren't] going to
change. So yes, now we are having serious problems with the [service] supply. The
service supply is insufficient, the service supply is poor quality.... [T] he sectors have
to get on this. I'm pushing for it, but they aren't responding to me. And what's more,
in all of the meetings I go to when I travel to the field, this subject comes up with
Juntos users. Service supply. The doctor isn't there, the teachers aren't there, et cetera.

Yet it was not only that clinics and schools were often closed. Reports of discriminatory behavior on the part of health and education service providers toward Juntos recipients also made their way into the offices of policy makers in Lima. The high-level expert at MIDIS continued: "They treat them really badly, no? They make them come, and then they treat them badly. They say, 'Oh you are the Juntos women, come tomorrow! Because they pay you!' No? . . . And make sure that they don't negotiate, for example: 'Ah, if you don't do this, I won't sign off [verifying that you fulfilled the coresponsibilities]. There is lots of this."

Discriminatory attitudes toward the rural and indigenous poor were a problem not only at the level of service delivery but also in spaces where policy decisions were made. While the more technical frustrations that were related to budgets and interinstitutional coordination were more often voiced in interviews, the issue of institutional discrimination also surfaced. The former president of the Juntos Directive Council suggested that ability to coordinate services was also impeded by the discriminatory attitudes of political leaders, who were unconvinced of the imperative to improve the conditions of poor rural and indigenous populations. ${ }^{10}$

In the context of bureaucratic barriers and institutional discrimination, one visibly frustrated high-level development expert that I interviewed gave a bleak 
forecast: "These sectors don't have a plan of improvement. It's not going to happen." Those responsible for Juntos were understandably concerned about their inability to ensure that the program's target population would encounter highquality services at schools and health clinics. What was the point of sending people to subpar services? In recent years similar concerns have become visible within program evaluation circles; researchers who were once unabashedly enthusiastic about the potential for CCTs to reduce poverty increasingly stress that long-term positive outcomes depend upon the provision of quality services (Cecchini and Soares 2015).

Poor quality notwithstanding, experts at MIDIS and Juntos continued to incentivize women and their children to use the health and education services available. This begged the question, On what grounds did experts justify the use of conditions?

\section{HOLLOWING OUT THE POLICY: FROM "ACCESS TO QUALITY SERVICES” TO ENFORCING CONDITIONS}

Policy makers knew that the public services available to the rural poor were inadequate, yet they continued to incentivize Juntos recipients to interact with them. This was perplexing, as a common argument for unconditional cash transfers in other parts of the world is that the poor quality and availability of services makes conditional grants unjustifiable. ${ }^{11}$ During my fieldwork I often asked policy administrators if conditionality was necessary. What about an unconditional cash transfer? The common response-that conditions were necessary to increase health and education uptake-often elided the issue of service quality and shifted responsibility for overcoming poverty to the poor.

The following excerpt from a MIDIS document that outlines the government's approach to addressing exclusion and to building the case for Juntos illustrated this shift in responsibility:

A sustainable reduction in exclusion requires a complex intervention.... But above all, it requires time: it is not possible to effect an immediate change in conditions that restrict the ability of people in the process of inclusion to take advantage of economic opportunities and enjoy high-quality public services. Nevertheless, there are Peruvian households today living in conditions of extreme poverty and vulnerability that cannot wait for new investment and programs designed to improve their lives. Furthermore, these homes shackle future generations to the same conditions of exclusion, as they have never been able to feed their children adequately or to pay the costs of health care and education." (MIDIS 2012c, 9, emphasis mine)

In the document, MIDIS acknowledges that poverty and exclusion are complex issues relating at least in part to patterns of investment that limit some people's access to opportunities and key resources. Yet in the same instance, blame is located 
with poor parents and their failures to overcome the barriers to health and education. In interviews, high-level experts echoed these charges and suggested that conditionality was necessary to mobilize poor people to overcome geographical barriers as well. One high-level expert explained the importance of conditionality to me as follows:

One of the pieces of evidence from which this program originates is that in the rural regions of Peru, many children are not using the poor service supply that exists. The gap in school attendance and use of health services between rural children compared with urban children is huge, and it doesn't reduce itself automatically. So we have to do something to ensure that rural children have the same opportunities as urban children. This is why it is basically a rural program; it's not that there aren't extremely poor people in Lima. There are. Lots. But these children go to school, because the school is four blocks from their house, and they receive teaching. The health post is ten minutes away; and [they can go] to the hospital. In the rural zones, this doesn't happen.

Instead of making it easier for rural families to access services, the state's response was to incentivize families to make the journey in spite of the difficulties. As stated by another high-level expert that I interviewed, "Supply of services is poor[,] . . . so you give incentives through a transfer so that [families] effectively meet the conditions."

Yet why, if services were poor, were rural families expected to use them?

\section{Deservingness}

One of the reasons why policy makers insisted on imposing conditions was related to public perception of deservingness. At the time of my fieldwork, there was an ongoing debate about Juntos in the Peruvian media. At the center of the debate was the question of what kind of behavioral change Juntos actually provoked. In particular, critics condemned the program for its supposed proclivity to foster dependency and for its unwillingness to invest in the types of infrastructure that would help the rural poor generate wealth themselves-for instance, irrigation systems to increase agricultural productivity (El Comercio 2013b, 2013a). ${ }^{12}$ This claim, which was not unique to the Peruvian program, has been disproved by a number of studies (Arroyo 2010; IEP 2009).

Despite evidence that Juntos did not foster laziness, public anxieties about giving cash to poor people persisted. According to the accounts of experts at MIDIS and Juntos, the conditional aspect of the program attended to these concerns. A former Directive Council president suggested to me that "when [poverty] is accompanied by social assistance, you can create a lot of dependency and paternalism. ${ }^{13}$ For example, 'I receive this because I'm poor and you have to give it to me, and I won't do anything on my part.' So I think that this type of [program] that comes with a commitment . . on the part of the beneficiary is positive." 
Conditionality was viewed as a way to ensure that the poor, rural, and indigenous communities that Juntos served displayed the appropriate levels of motivation to lift themselves-as the popular adage goes-out of poverty. According to another development expert I interviewed, "[MIDIS] shouldn't always be giving help and having people that don't want to make progress. [Poor people] can't live just getting, getting, getting." Anxieties about the poor's deservingness were pervasive, sticky, and contradictory; these views were often held by the very same authorities who insisted that social programs such as Juntos were a citizenship right.

Among experts at authoritative development institutions such as the World Bank, conditionality is widely viewed as a mechanism for managing public anxieties about dependency and deservingness, and achieving public buy-in (Fiszbein et al. 2009). These experts suggest that conditionality makes the redistributive aspect of the policy more "palatable" to taxpayers and voters: "It is possible, for instance, that taxpayers are more prepared to pay for transfers to those who are seen to be helping themselves than to other equally poor people who are seen to be lazy or careless. Some voters who object to unconditional 'handouts' may be less averse to 'rewards' to 'deserving' poor people who are investing in the health and education of their children" (Fiszbein et al. 2009, 60). This perspective understands conditionality as fostering a kind of social contract, "whereby society (through the state) supports those households that are ready to make the effort to 'improve their lives'-the deserving poor" (Fiszbein et al. 2009, 60, emphasis in the original).

Studies show that conditionality in and of itself, however, is not enough to achieve public buy-in. A World Bank analysis of sixty-five hundred newspaper articles about the Brazilian CCT found that the imposition of health and education conditions mattered to the public for a number of reasons (Lindert and Vincensini 2010). These included the perception that conditionality emphasized long-term impacts (whereas cash without conditions was limited to alleviating immediate poverty), ensured the adoption of parental behaviors deemed appropriate (sending children to school instead of work), and reduced the potential for the program to generate welfare dependency (assistencialismo). Interestingly, the public perception that conditionality mitigated the risk of dependency was neatly tied to a perceived connection to long-term impacts, which was the most important reason for imposing conditions. That said, conditionality increased public support for Brazil's CCT only when it was monitored. The monitoring of program recipients' compliance with conditions generated vital political legitimacy for Brazil's program.

My research suggested that data about women's compliance with conditions also generated legitimacy for the Peruvian CCT. Experts enforced program conditions, in spite of the poor quality of health and education services, at least in part because conditionality reduced anxieties about deservingness. My research also 
revealed another reason for the imposition of conditions, one that had to do with the metrics for success.

\section{Impact Measurement}

The policy makers and bureaucrats in Lima also incentivized women and their children to use the poor-quality services available because the key metrics for success encouraged them to. Juntos was subject to the results-based budgeting strategy of the Ministry of Economy and Finance, which monitored and promoted efficiency in public spending. Juntos, like other social programs, was required to produce particular kinds of data to prove that the public funding allocated to the program was money well spent.

The results-based budgeting strategy had a number of priority themes, including the incidence of chronic childhood malnutrition and maternal mortality, which related closely to Juntos's aims. Social programs affiliated with the strategy were required to show that they contributed to achieving targets related to those priority themes (MEF 2008, 11). For instance, in order to show that Juntos addressed chronic childhood malnutrition, the program was required to make progress relating to two indicators: proportion of children under thirty-six months with complete vaccinations; and proportion of children under twelve months of age who had completed the government-mandated set of growth and nutrition checkups. ${ }^{14}$ The requisite proportion was determined by dividing the number of Juntosaffiliated children who had obtained their vaccinations or their set of checkups by the total number of children in the target population of Juntos recipients (MIDIS 2012a). Other targets imposed on Juntos were operational and related to the percentage of pregnant women registered within the first trimester of pregnancy; the percentage of children registered with Juntos within thirty days of birth; and the elaboration of management documents that outlined processes for household affiliation and monitoring conditions (often referred to as verification of coresponsibilities), among other targets (MIDIS 2012a).

Notably, most of the targets were related to service usage, rather than quality. As a result, when Juntos demonstrated that it had sound processes for enforcing and monitoring conditions, its upper-level functionaries were able to claim the program's success and to secure continued financial support. After lamenting the state of health and education services in areas of Juntos intervention, a high-level development expert that I interviewed framed the success of the program as a matter of compliance with conditions: "[Juntos] is an incentives program so that boys and girls go to health and education. Continuously, and all boys and girls. And this objective is achieved. And this is what you must protect and preserve." Another high-level development expert that I interviewed referenced studies conducted by the World Bank that found a positive relationship between school attendance and completed growth and nutrition checkups. While acknowledging the very serious 
problems related to service quality, he emphasized that according to quantitative measures pertaining to service attendance, Juntos was a successful intervention, suggesting that "from this viewpoint, Juntos fulfilled its role."

The standard to which Juntos was held was related to a shift in institutional focus: Juntos went from striving to improve poor people's access to quality public services to making sure that poor people used services of whatever quality was available. A series of press releases in January 2013 on the Juntos website proclaimed that "the most important aspect of this program is that it mobilizes rural households to use health and education services in favor of their children" (UCI 2013). In interviews, experts spoke about the institutional turn in which enforcing and monitoring conditionality was emphasized: "I think the most important achievement of Juntos in the past year and a half has been the redefinition of its role- to focus on being a program that promotes human capital with a component of [poverty] alleviation, where the most important thing is verifying the behavior changes of the families, so that the boys and girls of these households actually use health and education services."

The quality of services, a much messier, more political and intractable issue to contend with, was constructed as someone else's problem. Policy makers and program administrators at the highest levels of MIDIS and Juntos insisted that service quality (or system strengthening) was the responsibility of the ministries of health and education-not the Ministry of Development and Social Inclusion, and not Juntos. I found this perspective to be prevalent. The following quote from a highlevel development expert I interviewed illustrates the logic: "The Juntos program, what it does is ensure that the poorest people use the universal services. But the universal services have to get better. But the Juntos program can't do this. This has to happen in the [health or education] sector. Because the obligation of the Juntos program is to ensure that children go to school every day. What happens inside the school, we'd love to help. But this isn't Juntos's job. Juntos's role is to ensure that the poorest people are going to take their kids to school."

Speaking to me about the "precarity" of health and education services, a highlevel expert directly responsible for the program insisted, "I can't do anything about this," and shared with me a guiding maxim: "Zapatero, a tus zapatos," or "Cobbler, stick to thy last." ${ }^{15}$ Policy makers' frustration at their perceived inability to effectively coordinate services was understandable. Yet the implications of an approach that passes off responsibility for a vital component of this program were grim. Earlier in that same interview, we had compared experiences of elite education-upon learning that I was earning my $\mathrm{PhD}$ at Cambridge, she related having graduated from Peru's excellent private university to attend graduate studies at an Ivy League school in the US. Like others charged with administering the country's social inclusion policy, she benefited from a high-quality education, the likes of which was unavailable to the hundreds of thousands of people who qualified for Juntos. 


\section{FROM POLICY TO PRACTICE: COORDINATING \\ CONDITIONALITY AND GATHERING DATA}

In order to be presented as a successful development intervention, Juntos was required to enforce and monitor conditionality. The Verification of Coresponsibilities Unit at Juntos headquarters in Lima was responsible for coordinating the conditional aspect of the program. I met with employees there one morning for what began as an interview with one staff member and turned into something more akin to a focus group. As I was led to the conference room by the original participant, additional staff seated at desks throughout the open floor plan were called or volunteered to join the discussion, until there were six of us, all women, seated around a large table in the conference room.

During the interview, the group spoke enthusiastically about traveling to rural areas of Juntos intervention, where they met with exemplary CCT recipients and related emotional stories about institutional attempts to involve the mothers in program implementation and local decision-making processes. Through these participatory experiments, most of which took place a few years before the interview, the staff learned about the women's lives: "In these . . . workshops that we went to in the regional headquarters, we listened to the mothers, and we ate lunch with them. We had breakfast with them, danced with them, we sang together. Everything. And we learned a ton, because it's one thing to think you know what the mothers think, and it's another to listen to the reasons why they do or don't take their child to school." These encounters, which staff suggested involved the "accompaniment" of Juntos mothers, informed the ways that the midlevel administrators thought about their work and the value of the Juntos program-they believed that Juntos played an important role in improving the quality of life and dignity of the families, with tidier and better educated children.

The participatory experiments did not last, however. In coordination with the increased institutional focus on conditionality discussed above, the work of the midlevel bureaucracy also shifted: "Now we've begun to refocus on the issue of compliance with coresponsibility, so that their children become more responsible citizens, because the mothers are now responsible for the education and health of their children, who, because of participating in the program, are going to be better people." During the interview, I inquired about how compliance with program conditions was monitored: "Well, this is all done with some forms that we elaborate here, for children's health and for education, and for pregnant women, so that they attend - they have to attend, right? What we verify is that children attend, from age six, or three in the case that they are in school starting at age three, [and before this their attendance] is verified at the [nearest] health post."

Verifying that conditions were met involved coordinating the frontline implementation work of Juntos staff called "local managers," who operated in the rural areas where Juntos intervened. Every two months, the Verification of 
Coresponsibilities Unit sent a stack of verification-of-coresponsibility forms to the regional offices. The forms were large, white paper documents; a regional Juntos administrator told me that she and her colleagues referred to them as "bedsheets." The forms captured information that high-level experts needed to report regarding the prescribed indicators of Juntos's impact. They arrived at the regional offices with Juntos mothers' names and identity documents listed down the left side of the page, and a series of check boxes that solicited data from health and education institutions about service uptake: children's school enrollment, attendance, and graduation; women's attendance at prenatal appointments; and children's attendance at health checkups, also prompting input of height, weight, and vaccinations administered. In a final column, the forms prompted a "yes" or "no," corresponding to whether a Juntos mother met the required set of conditions. If "no" was inputted on the form, the mother would not receive the next cash payment. When the program recorded high rates of compliance with program conditions, which it regularly did, high-level administrators were able to claim Juntos's success.

In theory, at the beginning of every two-month Juntos cycle (the cash transfer being made every two months) local managers were meant to deliver the verification forms to health clinics and schools in the districts they managed. There, over the course of two months, health and education personnel who had been trained by Juntos to handle the forms would fill them out with the required information. At the end of the cycle, local managers would collect the completed forms and return to the regional capital, where they would input the information into a centralized computer system. As evidence presented in the following chapters illustrates, there were no data-quality or verification mechanisms in place whereby women could verify or contest the validity of information that their local managers entered into the system.

This arrangement formed part of the unsuccessful agreement between Juntos and the Ministry of Health and Ministry of Education discussed above. Given Juntos's inability to enforce the health and education sectors' compliance with the agreement, the arrangement requiring health and education professionals to record compliance information on the "bedsheets" was unevenly implemented throughout the country. In 2012, 88 percent of health establishments in the department of Cusco filled out the verification-of-coresponsibility forms, while 46 percent of education establishments did the same. By contrast, in Cajamarca, o percent of health establishments and o percent of education establishments honored the agreement that same year (Juntos 2012). Other regions fell between these extremes, with a substantial number of them falling at or near o percent.

A qualitative evaluation at health and education establishments undertaken by MIDIS indicated several contributing factors to noncompliance among staff. Rural clinics and schools faced a high rate of staff turnover, which caused a delay in securing representatives to fill out the forms. The staff at the Verification of Coresponsibilities Unit also spoke about this barrier: 
Participant 1: What happens is that health or education staff rotate, changeParticipant 2: They rotate a lot, they rotate a lot.

Participant 1: But in the case of health, I think one of the problems is that many times the staff are [practicum students], they are about to graduate and they have to do a year of service in the communities, and so from time to time they rotate. It is not a person-a professionalwho stays for many years.

In such cases, the local managers found themselves responsible for training new staff on how to fill out the forms, which was time-consuming. The MIDIS study found that in other cases, staff were unaware of the agreements and the requirement to fill out the forms; and in yet others, school and clinic personnel reported that they did not have time to do it. These observations speak to the perception among health and education staff that Juntos was unrelated to the remit of their own establishments (MIDIS 2013a).

In response, Juntos administrators emphasized that the central focus of local managers' work would be monitoring compliance with program conditions. According to a high-level development expert that I interviewed, "In the majority of cases internationally, the verification of coresponsibilities is done by the health and education sectors ... but not [in Peru]. Here, Juntos does it, because the [health and education] systems are isolated, they don't work, and they don't enforce policy. So the strength of Juntos has to be to do verification of coresponsibilities through its field personnel." Practically, this meant that instead of "accompanying" Juntos mothers, to borrow the term from Verification of Coresponsibilities Unit staff, Juntos's frontline personnel were required to spend their time in the back offices of schools and clinics, rooting through attendance records and stacks of medical histories. Less time was to be spent listening to mothers' reasons for complying or not complying, and more time was to be dedicated to gathering the data requested by program headquarters in Lima.

\section{WOMEN AT THE SERVICE OF THE STATE}

How did women, the Peruvian state's "partners in development," fit into all of this? Central to Juntos achieving high rates of compliance was women's willingness to use the services as Lima required. Women made up 95 percent of all Juntos recipients, and the majority of MIDIS's program users overall were women. Juntos, like most other CCTs, had a policy preference for women to enlist in the program and assume responsibility for meeting the conditions. MIDIS did not, however, consider rural women to be a "target population" for its programs, and Juntos referred to women as program "users" rather than "beneficiaries."

During interviews, experts spoke about women's role in Juntos in a way that was unabashedly instrumental. The shiny new MIDIS offices were located on a busy, 
well-manicured boulevard in central Lima. In a boardroom located high above the whizzing traffic, Lydia and Armando, two besuited cabinet advisors laden with multiple, blinking Blackberries, labored to correct my unfortunate phrasing of Juntos as "directed" at women:

Armando: In reality, [Juntos] is directed at the household.

Lydia: Right. Precisely because of the conditionality, it is the woman that is in charge of taking the child to school and the medical post, and for signing the [conditionality] agreement.

Armando: Exactly. I think something that might help you understand Juntos is that, for example, if you go on the MIDIS webpage, and you look for programs, right? .. . In Juntos, it doesn't say women. It says households.

In addition to putting me in my place, the two technocrats underscored a significant shift in Latin American social policy. In recent years, social assistance targets such as "children" and "women" have been replaced with "households." For many, this semantic shift was intended to acknowledge the nuances of poverty, especially that women and children tend to cohabit and share socioeconomic conditions (Serrano 2005; Barrientos et al. 2008; Barrientos and Santibánez 2009). In principle, this is very sensible. Yet use of the term household also masked a number of inequities (Serrano 2005). In the case of Juntos, household members were selectively and unevenly implicated in program implementation and intended outcomes. For instance, as the technocrats at MIDIS indicated, Juntos audited women's compliance with program conditions-not men's, and not children's. At the same time, the explicit program objectives were all oriented to the benefit of children. Even in the case of pregnant women, the implicit intention was to improve the life chances of the unborn child rather than the expectant mother, as is the case with CCTs elsewhere (Molyneux 2006).

Feminist scholars have discussed at length the ways in which CCT design positions women as "conduits of policy" through which the state improves the lives of children (Molyneux 2007). My research with experts in Lima confirmed these design-related indictments. One high-level expert unabashedly defended the program's utilitarian approach to women: "Juntos, uses, literally, the woman as a means to get to the child. This, I know that it is very tough, that the feminists are not going to [like it] . . . but Juntos is not a program, nor is it designed, with an explicit gender component-i.e., the social construction that women and men are different is not here." She was quite right to speculate that feminists would find this approach to women and their labor objectionable-I left the interview more than a little prickled. To claim that the CCT was not gendered, however, was misguided. Juntos, like other CCTs, was not designed to improve gender relations-that is, the unequal relationship between men and women that systematically affords women less power. Juntos was, however, designed with a gender awareness - an 
understanding that men and women are assigned different social roles according to their biological sex (Molyneux 2007).

"Gender aware" approaches to development capitalize on gender norms, rather than seek to change them. In interviews, experts in Lima rationalized the gendered policy preference as a simple equation-little more than a matter of logistics. According to a member of the Juntos Directive Council, "It's the mother who dedicates herself to the child. And if this money is dedicated toward improving the child's conditions, the mother should administer it." Gender was important insofar as it related to the distinct social roles assigned to women and men; in this case it meant that women were the most useful means of achieving program aims.

It is well documented that equipping women with financial resources can empower them, and many of the world's best-implemented development interventions explicitly seek to have this impact. ${ }^{16}$ When the question of women's empowerment surfaced in interviews with Juntos's high-level experts, however, it was framed as a positive externality of the program: unintended, albeit not unwelcome. One high-level expert explained to me that fostering women's empowerment (or, for that matter, anything else related to women's well-being) was not a part of her job description: "I don't work on social themes linked to women-no. If there are positive effects, great. But I haven't done a single thing directly so that this happens." It was very clear that Juntos did not give the cash to women in order to empower them; rather, women received the cash because experts sought efficiency in their investment. ${ }^{17}$

Did it matter that women were instrumentally folded into program design? A logistical approach to gender is not necessarily problematic in and of itself. Given the well-established relationship between poverty and gender inequality, there was, however, an unsettling contradiction that emerged in the ways that experts responsible for Juntos spoke about women. In Peru today, women experience poverty at higher rates than men owing to a number of interlocking political, economic, and social causes. Women are more likely than men to be illiterate and to experience violence at the hands of an intimate partner. They are less likely to participate in formal paid labor and more likely to engage in unpaid and underpaid care work. They are less likely to own land. Women are less likely to participate in politics at the local and national level and, as a result, less likely to have their needs represented when decisions are made. In light of these trends, the claims that Peru's farthest-reaching program for inclusion does not need to address the needs of women bears further scrutiny.

Policy makers in interviews and advertisements for public projects held women up as the state's partners in development. Yet as Juntos focused less on access to rights and quality services and more on the enforcement of conditions, "partnership" appeared to entail little more than women's compliance with a schedule of tasks imposed by the state. Take, for instance, the verification-of-coresponsibility forms. These monitoring tools solicited data that permitted the state to know 
which women had complied with the conditions and which had not. What it took for women to comply, or the reasons they might not have complied, was never recorded on these forms. There was no space for local managers to record how many times a woman had to travel to a health clinic before she found it open, or how far she had to walk, while pregnant and with a baby on her back or children in tow. The forms did not solicit data on the quality of attention she received, whether the clinic was clean or adequately stocked, or whether the technician or nurse there treated her with dignity. Regarding education, the forms did not solicit information about the quality of education received, whether the teacher showed up to work, whether the library had books and the bathrooms had running water, or whether students graduated equipped with literacy and other skills necessary to secure a job in the formal economy.

The forms laid bare what was left of a well-intentioned policy to include, once the more complex issues of delivering on rights and providing access to quality services were passed off as someone else's responsibility. The work of women was rendered invisible to the state, despite their contributions being heavily relied upon. How can we make sense of a situation in which an institutional attempt at social inclusion was evacuated of its more substantive aims yet still deemed successful?

\section{THE “WILL TO INCLUDE”}

Anthropologist of development Tania Li contends that when policy makers and development practitioners stubbornly press forward with a policy that has obvious failings, they demonstrate a "will to improve" (2007). For Li, the will to improve "draws attention to the inevitable gap between what is attempted and what is accomplished," and it also points to "the persistence of this will-its parasitic relationship to its own shortcomings and failings" (1). Li's work acknowledges the good intentions of experts committed to improvement while also insisting that we look at how and why intentions go awry.

We might understand inequality as produced and reproduced through economic policies, political processes, and social and cultural institutions that allocate resources and opportunities unevenly (Mosse 2010; Elwood et al. 2016). When well-intentioned experts aspire to tackle problems of inequality such as poverty, they enter into a process of translating aspirations into action. This involves making a seemingly unwieldy problem wieldy; policy makers must delineate a manageable area of intervention, both thematically (what will the intervention try to change?) and demographically (who will the intervention target?). This process often involves the sidelining of what $\mathrm{Li}$ (2007) calls "political-economic questions," the "questions about control over the means of production, and the structure of law and force that support systemic inequalities" (11). These questions get at the heart of why people experience poverty in the first place, and so when they are sidelined, ambitious development interventions lose their substance. 
The Peruvian government set an ambitious agenda, one that included the rural poor; and Juntos's substantive aim to improve access to quality services was taken up by high-level and midlevel experts. Inequality in Peru has a markedly geographical character; while coastal Lima has benefited from generations of investment in infrastructure and services, rural Andean and Amazonian Peru-where Juntos's target population resides-has not received the same level of attention. As a result, the rural poor do not have access to the same level of care as wealthier urbanites. This reality was no secret. Yet when actors at the state institution were charged with including the rural poor, they were unable or unwilling to tackle the messy political-economic questions underlying the terrible state of health and education services in the rural countryside.

Instead of tackling the infrastructural and institutional conditions that made and kept poor people poor, the state focused its efforts at a scale that was much more manageable: the household. MIDIS framed poverty and exclusion as a lack of human capital, or capabilities. The root causes of persistent poverty and exclusion were to be traced to the failure of already poor parents to appropriately feed, educate, and invest in the health of their children. This view reflected the dominant contemporary approach to development driven by the World Bank that places children's capabilities at the center of poverty responses. In the 2006 World Development Report, the bank advocated making investments in children as a powerful mechanism for overcoming future inequalities at the same time as it evaded more "complex" political-economic questions, including land rights and taxation (Razavi 2007a). My document analysis and fieldwork with policy makers in Peru revealed that targeting the household had two important effects. First, it relieved the state of responsibility for creating the conditions in which poor people are made poor. Second, it gave credence to the view that children were shackled to poverty by the faulty behavior of their own parents.

Eliding complex dilemmas in favor of a focus on households and the behavior of the individuals within them was an example of what $\mathrm{Li}$ (2007) refers to as "rendering technical." She uses the term as shorthand for the set of processes by which political-economic questions are depoliticized and made "amenable to a technical solution" (Li 2007; see also Ferguson 1990; Schwittay 2011). While rendering seemingly intractable problems like poverty technical makes them more manageable, it also explains why so many well-intended development interventions fail. Development experts in Peru acknowledged that requiring poor households to use low-quality services limited the capacity of the program to deliver real change. Yet by narrowing the program focus to enforcing conditionality - and passing off responsibility for service quality to other experts located in other ministries, they were able to generate impressive compliance and service-uptake statistics. Equipped with these authoritative data, experts were encouraged to press on with an attempt to include the rural poor that they themselves recognized as flawed. 
The case of Juntos highlights how the metrics applied to improvement can bolster and facilitate persistence in the face of policy shortcomings and potentially even failures. What we might call "the will to include" was in fact facilitated by a much larger trend in contemporary development policy and practice: a measurement obsession. In order to illustrate this contention, I turn to a body of literature that critically evaluates the data-oriented turn in development.

\title{
SYSTEMATIC BLIND SPOTS AND \\ THE MEASUREMENT OBSESSION
}

\begin{abstract}
In poor countries we focus on health, agriculture, and family planning. Given a goal, you decide on what key variable you need to change to achieve it-the same way a business picks objectives for inside the company like customer satisfaction-and develop a plan for change and a way of measuring the change. You use the measurement as feedback to make adjustments. I think a lot of efforts fail because they don't focus on the right measure or they don't invest enough in doing it accurately.
\end{abstract}

BILL GATES, ANNUAL LETTER, 2013

For a variety of practical reasons, policy administrators systematically sidelined questions of equity and focused instead on a handful of metrics they knew to be poor indicators of the changes they originally aspired to effect. When interviews and even routine reading of local newspapers so easily revealed that Juntos's more substantive aspirations had been hollowed out, how is it possible that the program still markets itself as such a remarkable success? Clearly there is a blind spot here, but how was it produced?

To explore what I mean by blind spot, let us consider medical anthropologist Salmaan Keshavjee's analysis of "realms of programmatic blindness," in which he draws attention to "the original aims of projects that get lost or ignored" in pursuit of ideological adherence (Keshavjee 2014, 15). Keshavjee's ethnography details what happened in post-Soviet Tajikistan when foreign NGOs attempted to bring health care to the poor by creating markets for delivery of health products and services. This attempt was grounded in the neoliberal ideology of the day, which posited that free and private markets were the most democratic and efficient way of providing care. Yet as the intervention unfolded, data suggested that people's health was not improving as hoped. Instead of changing course, the NGOs stubbornly pressed forward with the creation of new health care markets. While acknowledging that the attempt was well intentioned, Keshavjee showed that, in the end, loyalty to an ideology obscured the original aim of the intervention itself. Priority was given to building markets, rather than to ensuring that poor people had access to health care. The poor were faced with markets selling health services they could not afford.

While Keshavjee wrote about an obsession with markets, a different set of political-economic forces was at play in the case of Juntos and the broader trend 
of making aid conditional. In Peru, experts knew that the inadequate quality and availability of health and education services was a barrier to achieving Juntos's aim of including the rural poor. However, the narrowly defined metrics for Juntos's success permitted them to replace a substantive vision of inclusion with a more manageable approach that ensured poor people used services, quality notwithstanding. We might understand the way Juntos unfolded as the result of a fixation with measurement, one that extends far beyond Peru.

Measurement, in the words of legal scholar Doris Buss, "includes the production and mobilizing of quantitative data, but also the array of reporting processes, monitoring systems, and paper trails" that have come to mark the everyday practices of a society smitten with numbers and auditing (Buss 2015, 381). In global health and development, "evidence-based development" and "results-based financing" determine which problems, and which solutions, receive funding (Liebowitz and Zwingel 2014). This shift reflects the reach of economic and corporate logic into the governance of social spheres (Merry 2011). Consider, for instance, the rise of "venture philanthropy" (Merry 2011) and the exceedingly influential philanthro-capitalist actors whose tastes and logics reflect years spent amassing wealth in commerce and tech, and who now turn their attention to solving the problems of poverty, disease, and environmental degradation. In his 2013 annual letter, Bill Gates, arguably one of the most powerful actors in global health and development today, made a case for why he believes that the kind of measurement practices found in the business world are imperative to solving poverty and the global disease burden. He suggested that measurement provides a productive feedback loop: the data it generates allow policy makers and development practitioners to identify the scope of a particular problem, whether they are making progress toward resolving it, and if not, when to change course. Taking this cue from the business world, funders of development interventions demand proof of a problem and evidence of results in order to ensure that their investments are opportunely located (see Merry 2011).

To be sure, the "demand for data" turn in development responds to legitimate concerns about efficiency and waste in development spending. Yet skeptics of this turn suggest that the burgeoning demands on policy makers and development practitioners to produce evidence of impact constitute a "measurement obsession" that needs to be critically assessed (Liebowitz and Zwingel 2014). First, what constitutes evidence in this trend is often limited, having been generated by a handful of numerically oriented indicators designed to facilitate comparison across widely different contexts (Merry 2011; Liebowitz and Zwingel 2014). ${ }^{18}$ Equally problematic, these quantitative indicators are assigned an aura of scientific or "objective truth" (Merry 2011; Liebowitz and Zwingel 2014). Feminist scholars have raised a number of concerns about what the imperative to measure means for gender equality and other matters of social justice. One of their primary concerns relates to the capacity of quantitative metrics to capture the things that matter to women. 
They point to an important and oft-overlooked question: what truths do numbers not capture?

Numeric indicators are orientated toward simplification: they "convert complicated contextually variable phenomena into unambiguous, clear, and impersonal measures" (Merry 2011, 84). On the one hand, this means that statistics are particularly useful for identifying patterns and facilitating comparison. On the other hand, this means that they are less apt to capture the messier, more complicated aspects of social life. For instance, statistics might tell us how many women have experienced violence by an intimate partner. Yet they are less apt to identify unexpected drivers of violence, to explain connections between seemingly unrelated phenomena like violence and women's access to transportation, or to identify, from the perspective of women, what elements of available support need to be maintained or improved and why. Liebowitz and Zwingel (2014) suggest that simplification "results from the exclusion of social dimensions that cannot easily be translated into categories, not because they are unimportant, but because they are rather complex and fluid" (356). As a result, statistical renderings of problems of a socioeconomic nature rarely provide the nuanced and contextual information that helps us understand what drives them. One of the great risks in the persistent demand for rapid and continuous quantitative data on program outputs is that our attention is diverted away from qualitative data that captures vital dimensions of social well-being - that is, the root causes and structural aspects (Buss 2015).

The measurement obsession produces a "self-fulfilling imperative: create indicators that are measurable and then require that social justice work be directed, even pigeonholed, to achieve progress on said indicators" (Liebowitz and Zwingel 2014,363 ). This dynamic was evidenced as policy makers and development practitioners in Lima navigated the fraught terrain of translating a substantive policy of social inclusion into a successful development intervention. While experts continued to speak of the Juntos program's rights-based vision, when it came to confronting their inability to deliver on these more substantive aspirations, they hid behind a handful of quantitative metrics. Recall that program financing was tied to these key indicators. By narrowing program focus to conditionality, they were able to produce impressive statistics related to service uptake and present Juntos as a success story. This move focused attention on women's compliance with conditions and, at the same time, diverted attention away from what the state did or did not do to ensure that mothers and their children encountered adequate services.

\section{CONCLUSION}

The quantitative measurement obsession that shaped program implementation in Lima obscured the conditions that produce poverty and the gendered costs of compliance. At the level of policy and program administration, turning a blind eye to political-economic questions was incentivized. Experts were conditioned 
to focus on changing the behavior of individual mothers, rather than on addressing the persistently poor quality of health and education services. While some of the institutional dynamics among MIDIS and the health and education ministries are unique to Peru, the broader policy narrative is not. Globally, statistics indicating impressive levels of compliance feed narratives about the success of CCTs, even though compliance is hardly evidence that these programs are delivering on the loftier aspects of their stated missions. Nonetheless, the pressure to focus on numeric data not only comes from national-level results-based budgeting but also the development banks and other external funding agencies that provide governments with the technical and financial support to implement CCTs and other social programs.

To be sure, tackling inequitable allocation of resources, institutionalized discrimination, and other complex drivers of poverty is difficult work. Yet the exclusion of such matters from the design, implementation, and measurement of development interventions limits the potential of these interventions to achieve their own stated aims. Moreover, it can produce a host of unintended consequences (Ferguson 1990); the messy questions do not, in the words of Tania $\mathrm{Li}$, just "go away" (2007, 124). Social policies that are blind to gendered, racial, and geographical elements of exclusion often end up reproducing the very inequalities they intend to address (Paredes and Thorp 2015). In light of this analysis, my next step in this book is to shed light on these blind spots using data derived from long-term ethnographic fieldwork. Research in the rural areas where Juntos was implemented illuminates complexities and hidden costs that the measurement obsession would have us not see. The following chapter shifts location to the rugged Andes mountains, where frontline state employees enforced conditions and where compliant mothers accessed services. 